Revista Signos 2010, 43(73) $179-209$

\title{
Conciencia metapragmática y la habilidad para producir narraciones escritas*
}

\author{
Nina Crespo \\ Ricardo Benítez \\ Lorena Pérez \\ Pontificia Universidad Católica de Valparaíso \\ Chile
}

\begin{abstract}
Resumen: El presente trabajo intenta establecer la relación entre el papel que juega la conciencia metapragmática en la comprensión oral y la habilidad para producir textos narrativos escritos. Es, a su vez, parte de un proyecto mayor que estudia las habilidades metalingüísticas y/o cognitivas que pudieran asociarse al desarrollo de la comprensión oral del lenguaje no literal en la edad escolar y las posibles diferencias en el desarrollo de la lecto-escritura en niños y niñas con variados niveles de comprensión del lenguaje figurativo. La conciencia metapragmática se iniciaría alrededor de los seis años e involucraría conciencia verbalizable de la diferencia entre lo lingüístico y lo contextual y un control reflexivo de esta relación en una determinada situación de comunicación (Gombert, 1992). Verschueren (2002) sostiene que los indicadores de la conciencia metapragmática funcionan como mecanismos de anclaje que localizan formas lingüísticas en relación al contexto, como señales o marcadores de interpretaciones reflexivas de los usuarios del lenguaje respecto de las actividades que realizan y como claves de contextualización. Los participantes fueron 82 niños y niñas de tercero básico a los cuales se les aplicó un test de conciencia metapragmática y un test de producción escrita, que fue evaluado por una escala holística focalizada. Los resultados muestran que a mejor desempeño en composición, aumenta el porcentaje de respuestas metapragmáticas y se concluye que la conciencia metapragmática no es sistemática en todas las situaciones comunicativas, sino que depende de la manera en que se relaciona el contexto con el lenguaje utilizado.
\end{abstract}

Palabras Clave: Conciencia metapragmática, lenguaje figurativo, test de conciencia metapragmática, escala holística focalizada.

* Proyecto FONDECYT No 1070333.

Recibido:

9-III-2009

Aceptado:

15-III-2010
Correspondencia: Nina Crespo (ncrespo@ucv.cl). Instituto de Literatura y Ciencias del Lenguaje, Pontificia Universidad Católica de Valparaíso. Avenida Brasil 2830, piso 9, Valparaíso, Chile. 


\title{
Metapragmatic awareness and writing skills
}

\begin{abstract}
This paper attempts to establish a relation between the role played by metapragmatic awareness in oral comprehension and the skill to produce written narrative texts. It is also part of a greater project that looks at metalinguistic and/or cognitive abilities that might associate with the development of oral comprehension of non-literal language in school ages and the possible differences in the development of reading and writing in boys and girls with distinct comprehension levels of figurative language. It is believed that metapragmatic awareness starts at six years of age and that it involves verbalized conscience of the difference between language and context plus a reflective control over this relation in a given communicative situation (Gombert, 1992). Verschueren (2002) argues that the indicators of metapragmatic awareness work as (a) mechanisms that seek linguistic forms relative to the context; (b) reflective interpretation signals of the activities language users do; and (c) contextualization cues. The participants were 82 third-graders who took a metapragmatic awareness test as well as a writing test, which was graded according to a focalized holistic scale. Findings show that the better performance in composition, the more metapragmatic responses, and it is concluded that metapragmatic awareness is not systematic in all communicative situations but depends on the way the context relates to the language used.
\end{abstract}

Key Words: Metapragmatic awareness, figurative language, metapragmatic awareness test, focalized holistic scale.

\section{INTRODUCCIÓN}

Una vez adquirida la lectoescritura, los niños ingresan al universo de la cultura alfabetizada en la cual deberán desempeñarse cada vez con más eficiencia. Para lograr lo anterior, los pequeños estudiantes deben producir, entre otras cosas, textos escritos para expresar -cada vez más adecuada y autónomamente- ideas, cuentos o su saber acerca de algún tema. Sin embargo, en la literatura especializada se señala que el desarrollo de esta habilidad para componer textos escritos no ocurre en forma óptima en todos los niños, ni en Chile (Sistema de Medición de Calidad de la Educación (SIMCE), 2007, 2008, 2009), ni en otras partes del mundo. Las razones para esta dificultad o lentitud en este desarrollo pueden ser de naturaleza externa, como la metodología que se emplea para enseñarla, la didáctica que implica los materiales con la que se enseña, o la influencia de otros medios de comunicación; o bien, las razones pueden ser internas, como la falta de motivación por escribir, problemas en la memoria de trabajo, o bloqueos mentales del escritor. También puede darse el caso que ocurra una combinación de factores internos y externos. Entre estos últimos, Puyuelo y Rondal (2003) sostienen que la habilidad metapragmática -la conciencia y el autocontrol de la comprensión y producción lingüística oral-, favorece un aprendizaje más eficaz de la lengua escrita. Junto con lo interesante de esta afirmación, pareciera ser teóricamente congruente con el hecho de que a mayor control de las relaciones entre contexto y mensaje lingüístico oral, el sujeto es capaz de ideacionar 
de manera más adecuada la situación retórica, o representación mental de ese contexto no evidente en la escritura.

A partir de lo anterior, este artículo intenta establecer empíricamente la posible relación entre la conciencia metapragmática oral y la habilidad para producir en forma escrita textos narrativos escritos por niños y niñas de tercero básico. De esta manera, se busca observar un vínculo más sutil entre el dominio oral de una lengua y la producción escrita de la misma. Puede considerarse que dar cuenta de esas relaciones permite vislumbrar alternativas didácticas para el desarrollo de la escritura.

\section{Marco Teórico}

\subsection{Conciencia metalinguíistica y conciencia metapragmática}

Extendiendo el concepto de conciencia metalingüística al conocimiento y uso del propio lenguaje, tanto Karmiloff-Smith (1994) como Gombert (1992) señalan la existencia de una conciencia metalingüística entendida como conocimiento y regulación. Concretamente, Gombert (1992) sostiene que la noción de metalingüística esbozada por él es diferente a la idea de función metalingüística planteada por Jakobson (1963). Para este último, la función metalingüística tiene que ver con aquel rol que cumple el lenguaje para referirse al lenguaje. Por ejemplo, en la expresión 'La palabra casa es un sustantivo', el lenguaje estaría cumpliendo con dicha función, ya que estaría tratando acerca de sí mismo como tema u objeto de conversación. Sin embargo, para Gombert (1992) los alcances del término tienen un sesgo más psicológico, pues afirma que la conciencia metalingüística tiene que ver con el control consciente que cada individuo ejerce sobre su propia lengua y, en ese sentido, podría hablarse de cognición acerca del lenguaje. Bialystok (1992) considera que dicha conciencia es equiparable a uno de los dos componentes de lo metalingüístico: el control del procesamiento atencional, es decir, la atención selectiva a diferentes representaciones o a diferentes aspectos de una representación a medida que los problemas lingüísticos se resuelven.

Tanto Puyuelo y Rondal (2003) como Flórez-Romero, Torrado-Pacheco y Magnolia-Mesa (2006) señalan que existen distintas tesis con respecto al desarrollo de las capacidades metalingüísticas. Concretamente, Flórez-Romero et al. (2006) señalan dos posturas teóricas diferentes: aquella que defiende que este desarrollo es un producto de la regulación general del sistema cognitivo y otra que propone que dichas habilidades dependen exclusivamente del desarrollo del lenguaje. En el primer grupo, cabe contar autores como Bialystok (1992) y Van Kleeck (1994), quienes, al explicar los procesos que subyacen a las habilidades metalingüísticas, sugieren que estas habilidades requieren del dominio cognitivo general. Especialmente, Van Kleeck 
(1994) y Levy (1999) consideraron la teoría de Jean Piaget, relacionada con los estadios de desarrollo cognitivo, para explicar la emergencia de la capacidad metalingüística. Para estos autores, cuando los niños evidencian cierto comportamiento metalingüístico, este se relaciona con la etapa de desarrollo cognitivo en la que se encuentran.

Flórez-Romero et al. (2006) hacen hincapié en dos cualidades que Piaget (1987) le atribuye al pensamiento de los niños pre-escolares: la centración e irreversibilidad. La centración explica el motivo por el cual los niños durante una situación comunicativa controlan exclusivamente la fluidez del diálogo. Así, la característica de centración del pensamiento permite conjeturar que los sujetos solo pueden concentrarse en un aspecto durante una situación y, en el caso de la comunicación, tienen en cuenta el significado, que es, para ellos, lo más importante. La irreversibilidad se refiere a que los sujetos pre-escolares no pueden ir de un paso $\mathrm{A}$ a un paso B y volver al paso A. Estos niños estarían, según Piaget (1987), en una etapa pre-operacional $y$, en cuanto al lenguaje, demuestran que manejan exclusivamente la forma o el significado y no pueden realizar procesos de reversibilidad que les permitan devolverse en el discurso para analizarlo (Van Kleeck, 1994). De esta manera, Levy (1999) señala que los niños menores de seis años demuestran un desempeño metalingüístico pobre, porque su forma de pensar les impide separar la forma y el significado del lenguaje en una situación comunicativa y así considerar cada elemento por separado. El hecho de que este limitado desempeño metalingüístico empiece a enriquecerse a partir de los seis años indicaría, según Van Kleeck (1994), que los sujetos han pasado a una nueva etapa del desarrollo cognitivo.

Gombert (1992), por otra parte, afirma que el desarrollo metalingüístico depende intrínsecamente del desarrollo del lenguaje. Corroborando esta idea, Chaney (1994) lleva a cabo un estudio en el cual compara niños de diferente clase social, cuyos padres tenían conceptos diferentes respecto de la alfabetización y cuyo nivel de desarrollo lingüístico era diferente. La autora concluye que el conocimiento del lenguaje es lo que más podría predecir el surgimiento de una conciencia metalingüística.

Gombert (1992), coincidiendo con Karmiloff-Smith (1994), sugiere que el desarrollo metalingüístico se produce en tres fases: 'fase de habilidades iniciales, fase epilingüística' (tomando la noción de Culioli, 1990) y 'fase metalingüística'. Hablar de fases y no de etapas permite considerar cierta recursividad. Para estos autores, un niño puede estar cursando varias fases a la vez y aplicándolas de maneras diferentes en diversos microdominios y en situaciones distintas. Las dos primeras fases ocurrirían de manera más o menos sistemática, mientras que la tercera dependería del contexto.

En la adquisición de las habilidades lingüísticas iniciales, el niño aprende pares unifuncionales, donde una forma lingüística corresponde a un determinado contexto. Halliday (1975) señala 
una etapa inicial muy similar en su enfoque funcionalista de la adquisición del lenguaje. Sin embargo, en esta visión, apoyada por Karmiloff-Smith (1994), dicho proceso no sería únicamente guiado por el uso. El niño partiría con pre-programaciones innatas de las habilidades lingüísticas de base y aprendería los pares funcionales gracias a la mediación del modelo lingüístico presente en el entorno.

Dada la diversidad intrínseca del lenguaje, la estabilidad de la primera fase es cuestionada por el aumento de la extensión y complejidad de los modelos de los adultos. A partir de allí, los pares forma-función son sustituidos por formas multifuncionales, cuyo uso el sujeto administra en una suerte de ajuste automático. Esta fase es caracterizada como epilingüística y se produce por una reorganización en la memoria a largo plazo de los conocimientos implícitos acumulados dentro de la primera fase. El término epilingüístico fue acuñado por Culioli (1990), donde el prefijo 'epi' de origen griego, se refiere a un 'trabajo sobre' el idioma que, en realidad, es un hacer preliminar indispensable para llegar 'más allá del' uso puramente instrumental de la lengua. En el marco de la teoría del desarrollo metalingüístico, con este rótulo se identifican aquellas actividades de control que el sujeto lleva sobre su propio lenguaje pero lo hace inconscientemente, siendo una fase anterior a un uso más reflexivo, más deliberado y más explícito.

Puyuelo y Rondal (2003) señalan dos diferencias fundamentales entre la visión de KarmiloffSmith (1994) y la de Gombert (1992). Karmiloff-Smith (1994) sostiene que en la etapa epilingüística se reorganiza la información de la fase anterior (adquisición). En cambio, Gombert (1992) plantea que esta reorganización surge de la necesidad de interrelacionar estos conocimientos de la primera fase con otros recientemente descubiertos acerca de las mismas formas lingüísticas o acerca de otras formas que están asociadas con ellas y están en curso de apropiación. Otra diferencia apunta a cuál es la índole de la información que está actuando en esta etapa: mientras que para Karmiloff-Smith (1994) en esta fase la reorganización es impermeable a las influencias externas, Gombert (1992) afirma que -si bien la función principal de esta fase es una articulación interna de los conocimientos implícitos, que permitirá al sujeto el dominio funcional no consciente del sistema-, la elaboración de las reglas que rigen el uso de las formas lingüísticas viene determinada por aquello que el niño descubre acerca de dichas reglas en los funcionamientos lingüísticos en situación.

Finalmente, la etapa metalingüística está relacionada no solo con la capacidad de reflexionar y autorregular el propio lenguaje, sino también con la posibilidad de explicitar esta conciencia que se posee del propio código. Esta fase no ocurre de forma totalmente sistemática y homogénea: los hablantes suelen ser más auto-reflexivos en algunos aspectos del lenguaje que en otros y esto parece depender de las características de cada sujeto y de los diversos niveles del lenguaje que debe considerar. Así, por ejemplo, la conciencia metafonológica es una de las pri- 
meras que se desarrolla en el niño e incluso es motivada en los planes educativos preescolares, ya que ella sería facilitadora de la adquisición de la lecto-escritura inicial (Arnáiz, Castejón, Ruiz \& Guirao, 2002).

Ahora bien, Gombert (1992) analiza la habilidad metalingüística considerando diversos niveles de la lengua en los que ésta podría enfocarse: fonético, semántico, sintáctico, textual y pragmático. De ellos, el presente trabajo considerará la conciencia metapragmática. Gombert (1992) y Verschueren (2002) la visualizan involucrada en el uso tanto expresivo como comprensivo del lenguaje oral; la definen, además, no solo como un saber acerca de las relaciones entre contexto y mensaje lingüístico, sino también como conciencia y autocontrol de la comprensión y producción lingüística en dicha modalidad comunicativa. En este trabajo se considerará esta propuesta en el entendido de que la conciencia metalingüística relacionada con la lengua escrita considera otros factores y, por tanto, puede encuadrarse en lo que se ha denominado metacomprensión y metaproducción (Peronard, Crespo \& Velásquez, 2000; Mateos, 2001).

A partir de la definición de metalingüística en general, Gombert (1992) considera que todos los niños usuarios de una lengua adquieren la conciencia metapragmática también en fases distintas. La de adquisición inicial se caracteriza por la utilización de parte del niño de las primeras formas en ciertos contextos. La fase epipragmática puede ser descrita de manera similar a la epilingüística, pero sus alcances se restringen a las relaciones entre lenguaje y contexto. Cuando el niño da respuestas enmarcadas en esta fase, ve lo verbal y lo no verbal como un todo indiferenciado, sin discriminarlos explícitamente (Gombert, 1992). Sin embargo, esta no distinción no implica necesariamente muchos errores en el uso, porque el pequeño realiza ajustes automáticos entre ambos tipos de información (posee un dominio epipragmático); solo comete algunos traspiés de interpretación cuando dicha relación no es clara. De esta manera, el niño puede fallar en la comprensión al enfrentarse a enunciados cuya relación con el contexto no es totalmente evidente, como en general sucede con el lenguaje figurativo.

Finalmente, la fase metapragmática se iniciaría alrededor de los seis años e involucraría conciencia de la diferencia entre lo linguístico y lo contextual que es susceptible de ser verbalizada y, en consecuencia, un control reflexivo de esta relación en una determinada situación de comunicación. Cuando empieza a manejarse metapragmáticamente, el sujeto es capaz de explicitar las relaciones forma lingüística/contexto en la producción e interpretación de los mensajes lingüísticos y, paralelamente, se produce el desarrollo de su capacidad de comprender formas no literales como la metáfora y la ironía. Sin embargo, la habilidad metapragmática no se aplica en forma sistemática a todas las situaciones: un sujeto podrá evidenciar un nivel de comprensión o producción lingüística evidentemente metapragmático en ciertas situaciones y uno epipragmático en otras. Es decir, el control consciente característico de esta fase no se da 
solo con la edad; un niño mayor de seis años no da respuestas metapragmáticas todo el tiempo, sino que estas dependerán de la complejidad tanto del mensaje lingüístico, como del medio contextual en el cual éste tiene lugar y con el cual se relaciona.

Para completar esta noción de metapragmática, es necesario acudir a la visión de Verschueren (2002) respecto de cuáles serían las señales que le permitirían al usuario de una lengua ajustar lo lingüístico con lo no lingüístico cuando se autorregula. Para Verschueren (2002), los indicadores de la conciencia metapragmática funcionan de tres maneras en el lenguaje en uso: como mecanismos de anclaje que localizan formas lingüísticas en relación al contexto (deícticos, por ejemplo, los pronombres); como señales o marcadores de interpretaciones reflexivas de los usuarios del lenguaje respecto de las actividades que realizan (indicadores léxicos, por ejemplo, adverbios oracionales); y como claves de contextualización (por ejemplo, cambios prosódicos, gestos o sonidos).

\subsection{La producción escrita en la educación formal}

A los seis años, los niños de la cultura occidental reciben en sus colegios una instrucción que les permite manejar la modalidad escrita de su lengua materna, tanto para comprender textos escritos como para producirlos. Este es el primer paso en su acceso al universo de la cultura alfabetizada, acceso que lograrán en forma plena produciendo, cada vez más adecuada y autónomamente, diversos tipos de textos. El desarrollo de la habilidad para hacer uso eficiente del discurso escrito es lento y ocurre en el transcurso de toda la educación formal. Asimismo, requiere que el estudiante se represente una situación retórica del escrito, es decir, su tópico, su posible destinatario y el propósito del escrito (Bitzer, 1966; Brinton, 1981; Ede \& Lunsford, 1984; Flower \& Hayes, 1981; McKee \& Porter, 2008; Porter, 1992; Vatz, 1973, entre otros). Esta representación le permite suplir la carencia de un contexto empírico y perceptible, típico de la lengua oral.

Ahora bien ¿qué es la situación retórica? Se puede definir como una representación mental que guía la escritura del sujeto. Anteriormente, se señaló que ésta se compone al menos de tres elementos básicos, a saber, el tópico, los lectores y el propósito. El tópico necesita ser desarrollado de tal manera que los destinatarios del texto comprendan el propósito para el cual se produjo un determinado texto y se deberá mantener a lo largo del texto por medio de una línea argumental coherente, a través de nexos cohesivos, de ejemplos y del conocimiento de cómo y cuándo focalizarlo al máximo, entre otras cosas.

Lo anterior, que a simple vista parece no presentar grandes dificultades, se complica cuando el escritor debe contar con una representación mental de sus lectores a los cuales va a dirigir 
su texto, una complicación que surge especialmente porque, a diferencia de lo que ocurre en la mayoría de los casos cuando se produce lenguaje oral, los destinatarios de un texto por lo general no se encuentran presentes al momento de ser escrito el mensaje. Esta situación se agrava aún más cuando los lectores son ficticios o imaginados en tareas de escrituras escolares y se alivia de cierta manera -por parte de los estudiantes- cuando estos saben que el único destinatario de sus producciones escritas es su profesor. Este elemento de la situación retórica es determinante del registro lingüístico que se utilizará en el texto, es decir, el escritor deberá adaptar el uso del lenguaje a unos lectores determinados hacia los cuales el escritor que desee escribir un texto comunicativamente efectivo debe demostrar empatía como también conocimiento de rasgos característicos de dichos destinatarios para que la comprensión de ese texto se lleve a cabo sin mayores dificultades. Entre estos últimos, se pueden contar rasgos como el nivel de educación, la edad, el sexo, y el conocimiento que dichos lectores tengan del tópico. En el caso particular de la investigación de la cual se darán detalles más adelante, los participantes -niños de entre 8 años y 8 años 11 meses- recurrieron a estrategias de compensación para suplir la carencia de lectores o de un interlocutor que no estaba presente. Estas estrategias se manifestaron en ilustraciones, dibujos y esquemas, que 'compensaron' dicha ausencia. Sin embargo, no se sabe a ciencia cierta si estas estrategias fueron desarrolladas en forma consciente $o$ inconsciente, lo cual creemos amerita una posible investigación posterior.

El tópico corresponde a la respuesta a la pregunta ¿acerca de qué se va a escribir? Es una pregunta que, generalmente, se contesta con facilidad si el escritor tiene el conocimiento de mundo suficiente como para producir texto, tal como sería el caso de la producción oral. Por el contrario, al faltar ese conocimiento de mundo, el tópico se hace difícil de desarrollar y el escritor deberá buscar recursos que lo apoyen. El tópico es el material principal del texto según el cual se van construyendo las macroproposiciones que conforman la macroestructura (Benítez \& Velásquez, 2000). En el caso particular de esta investigación, el tópico fue proporcionado a los participantes, es decir, fue algo externo a ellos -como es habitual en el ámbito escolar- y los participantes no tuvieron que recurrir a fuentes externas, por cuanto la naturaleza del género que se les solicitó (narración) necesitaba mucho más imaginación y conocimiento del género en cuestión que conocimiento de mundo.

Finalmente, el propósito de un texto está estrechamente relacionado con la(s) intención(es) del escritor, lo cual derivará en el género o tipo de texto que se desea producir. Este elemento de la situación retórica tiene que ver con los objetivos o metas que el escritor desea alcanzar y pensar acerca de propósitos en la producción escrita significa pensar en las fuerzas que motivan a las personas a escribir. Persuadir a un lector a hacer algo o narrarle un cuento son solo dos ejemplos de los propósitos con los cuales los escritores manifiestan sus intenciones en la construcción de sus textos. Para ello, los escritores deben tener un conocimiento del género 
textual con el fin de plasmar esas intenciones de la manera más efectiva. Concordando con lo anterior, Williams (1998) lo denomina 'propósito retórico', el cual incluye las metas personales del escritor para producir un texto determinado. Estas metas no son iguales al objetivo de un texto, que puede ser informar, argumentar o persuadir. El propósito retórico es acerca del escritor, en tanto el objetivo de un texto es acerca de los lectores y el efecto que el texto debiera tener sobre ellos.

Se debe dejar en claro que en los tres elementos de la situación retórica que se acaban de describir son esenciales los elementos básicos. Hay otros autores que, aparte de esos tres elementos, incluyen otros, como por ejemplo, para Chafee, McMahon y Stout (2002) el escritor mismo -su personalidad, su estilo de escritura, su conocimiento del tópico- es uno de los componentes de la situación retórica tan importante como se consideran los otros tres; o Hyland (2007), que contempla dentro de la situación retórica no solo las exigencias de la tarea de escritura, sino también el contexto tanto físico como todo lo no físico que puede influir en la producción.

\section{Metodología}

\subsection{Los sujetos}

Los participantes en esta investigación fueron estudiantes de 8 a 8 años y 11 meses que cursaban el tercer año básico en 2008 y asistían a colegios municipalizados y subvencionados co-educacionales en dos ciudades de Chile: Viña del Mar y La Serena. Los instrumentos utilizados para evaluar la producción de textos narrativos y medir la conciencia metapragmática se aplicaron a 165 y 103 alumnos, respectivamente. A partir de allí, se depuró una muestra correspondiente a los niños que habían rendido ambas pruebas y que contaba con 82 participantes, de los cuales 49 eran de sexo masculino y 33 de sexo femenino.

\subsection{Los instrumentos de medición}

Con el fin de medir la conciencia metapragmática de los participantes, se diseñó el instrumento Test de Conciencia Metapragmática (CMP) y para medir la producción escrita se elaboró un Test de Composición Escrita que fue evaluado por medio de una Escala Holística Focalizada (EHF).

\subsubsection{La medición de la conciencia metapragmática a través del CMP}

El instrumento de conciencia metapragmática es un tipo de software cuya fundamentación teórica y confiabilidad estadística fue dada a conocer por Crespo (2009), quien señala que dicho instrumento mide algunos aspectos de la conciencia metapragmática, más específicamente el 
ajuste entre un elemento deíctico y su contexto. Para ello, el test -que cuenta con 29 ítemspresenta tres tipos de ejercicios en los cuales se producía un desajuste en forma intencionada entre la forma lingüística y el contexto no lingüístico. Los desajustes eran de tres tipos que imitan los ejercicios comentados por Gombert (1992): a) Referente Ambiguo, cuyos ítems presentaban una expresión referencial que no especifica bien su referente. Por ejemplo, se presentan cuatro gatos, dos de ellos con collar (uno rojo y otro amarillo) y se le da la instrucción al niño de que "elija el gato con collar" (Anexo 1); b) Instrucciones Ambiguas, ejercicio que consiste en darle instrucciones erróneas o incompletas al sujeto que está siendo evaluado para participar en un juego o realizar una acción y que fue utilizado inicialmente por Flavell (1985) (Anexo 2); y c) Diálogo Observado, ejercicios en los cuales el sujeto observa un malentendido entre dos personas debido a la falta de precisión del emisor del enunciado y debe emitir un juicio acerca de dicho malentendido (Anexo 3).

En esta prueba hay tres posibilidades de respuesta. En la primera, el participante se da cuenta del desajuste entre el elemento deíctico y contexto extralingüístico, y logra explicitarlo; por ejemplo, en el ejercicio Referente Ambiguo de más arriba, el niño señala que hay dos gatos con collar y pide una explicación. Por este motivo, se considera que ha dado una respuesta metapragmática y se le asignan dos puntos. En la segunda y la tercera opciones, el participante se comporta de manera epipragmática, porque evidencia ajustes automáticos entre la información lingüística y no lingüística, cometiendo algunos errores de interpretación. Sin embargo, es posible distinguir dos niveles dentro de lo epipragmático. En el primer nivel, el participante se da cuenta del desajuste, pero es incapaz de precisar verbalmente cuál es éste; así, en el mismo ejemplo anterior de Referente Ambiguo, el niño señala que no entiende y que no puede responder; por ese motivo, se le asigna un punto, ya que evidencia un nivel de conciencia incapaz de ser explicitado (Karmiloff-Smith, 1994). En el otro nivel, el participante recibe cero puntos, ya que su respuesta es errónea al no darse cuenta del desajuste lingüístico/extralingüístico; de esta manera, en el mismo ejemplo anterior de Referente Ambiguo, el niño señala cualquier gato con collar.

\subsubsection{La medición de la producción escrita a través de una escala holística focalizada}

A los participantes se les solicitó que produjeran una narración, género textual que se cubre como contenido didáctico en el nivel de escolaridad elegido; por tanto, se asumió que los participantes estaban familiarizados con los elementos que componen dicho género. Esta narración se evaluó a través de una Escala Holística Focalizada, la cual se basa en el trabajo de White y Venneman (2000), quienes la diseñaron para medir el mismo género textual en estudiantes de cuarto año básico. Según estos autores, esta escala, por un lado, se ajusta especialmente a los 
textos narrativos debido a la dificultad que presentan para evaluarlos y, por otro, fusiona dos tipos de escala empleadas típicamente para medir la composición escrita: la holística y la del puntaje de rasgo primario. La primera permite clasificar los textos producidos de acuerdo a su calidad, generalmente en baja, media y alta, para lo cual se necesita la competencia de al menos tres jueces para poder aplicarla en forma efectiva. En cambio, la segunda -la escala del rasgo primario-, permite fijar la atención en solo ciertas características de la composición escrita, por ejemplo, cuán bien ha sido desarrollado el tópico o con cuánta efectividad se ajusta a un registro lingüístico apropiado a los destinatarios, y no necesitaría de más de un juez para aplicarla correctamente por la explicitud de los rasgos que considera.

La EHF se plasma en una rúbrica que, al igual que todas las rúbricas utilizadas en evaluación, consta de un ítem y sus respectivos descriptores a los cuales se les asigna un determinado puntaje. En el caso particular de esta investigación, a los ítems se les denominó 'tipo de respuesta', siendo 'respuesta' el producto entregado por el participante, es decir, la composición narrativa misma. Las respuestas (o composiciones) fueron evaluadas de acuerdo a la siguiente clasificación: Insatisfactoria (1), Insuficiente (2), Desequilibrada (3), Suficiente (4), Idónea (5) y Excelente (6). Los números en paréntesis indican el puntaje asignado a cada respuesta (ver Anexo 4).

La aplicación de la prueba de composición escrita requirió no solo la capacitación de dos jueces expertos para poder evaluarla en forma efectiva, sino también la capacitación de ayudantes de investigación para que pudieran aplicar y llevar a cabo las instrucciones (ver Anexo 5) en forma idéntica en los diferentes cursos que facilitaron este estudio. A los participantes se les dio 15 sugerencias de tópico acerca de los cuales podían escribir, como también se les mostró imágenes (en una pantalla que se ubicó al frente de la sala de clases) con la intención de que estos se inspiraran con mayor rapidez. Lo anterior se decidió con el fin de evitar en lo posible el bloqueo que podrían haber experimentado los participantes al solicitarles escribir una narración sin mayor preparación o previo aviso, considerando el corto tiempo con el que contaban para producir por escrito (una hora de clase).

Los tópicos que formaron parte de las sugerencias fueron tópicos recurrentes extraídos del libro Historias de Grandes Pequeños, en cuya primera edición de 2006 se recopilan narraciones escritas por estudiantes de enseñanza básica. Como nuestros participantes eran de tercer año básico, solo se seleccionaron los tópicos acerca de los cuales los niños de ese nivel de escolaridad habían escrito y que posteriormente fueron publicados en el libro mencionado. Las imágenes que se les mostraron con los mismos propósitos anteriores fueron seleccionadas de la Internet según criterios emanados del conocimiento del mundo infantil que posee el equipo de investigación. Estas dos modalidades para asistir en el proceso de inspiración fueron efectivas, 
según se puede constatar por la cantidad de composiciones que entregaron los niños como respuesta a la tarea de escritura. La cantidad era importante en esta primera etapa; la calidad de las composiciones -en una segunda etapa- se evaluó con la escala a la cual se hace mención en el primer párrafo de este apartado. Algunas muestras transcritas textualmente de las composiciones de los participantes se encuentran en el Anexo 6.

Debido al corto tiempo asignado, a todos los participantes se les solicitó que escribieran solo una composición. Se les entregaron dos hojas de papel en blanco; una para que escribieran su composición y otra por si deseaban hacer un borrador de la misma.

Los ayudantes de nuestra investigación, enviados a los diferentes colegios para que administraran la tarea de escritura, fueron estudiantes en práctica de Castellano y Comunicación tanto de la Pontificia Universidad Católica de Valparaíso como de la Universidad de La Serena. Si bien tenían conocimiento del género que se pretendía evocar en los participantes, estos ayudantes fueron igualmente capacitados para que los instruyeran acerca de cómo realizar la tarea de la mejor manera posible, leyendo junto con ellos las instrucciones, preguntando si tenían dudas, explicando la función que cumpliría la segunda hoja (borrador) y estipulando la longitud del texto que debían producir. Por el bajo nivel de escolaridad de los participantes, se asumió que sus habilidades no les permitían desarrollar otro tipo de género textual que no fuera el narrativo, como así lo evidencian los programas del Ministerio de Educación y lo confirma la experiencia con el mundo infantil de los investigadores.

Los jueces que evaluaron las composiciones se capacitaron por medio de la lectura de cada uno de los descriptores que conforman la escala y de clarificar todo tipo de descriptores dudosos o ambiguos. Cada uno de los tres jueces (D, R y P) leyó todas las composiciones y los puntajes que ellos asignaron se sometieron a un análisis estadístico para validar la escala, consistente en el cálculo del coeficiente de correlación de Pearson, análisis de varianza paramétrico (ANOVA) y un análisis de varianza no-paramétrico (Kruskall-Wallis) (R Development Core Team, 2006). A través del coeficiente de correlación de Pearson se obtuvo que existe asociación lineal directa entre los puntajes, siendo mayor entre los jueces $R$ y $P$ ( $r=0.78)$. En forma complementaria, se realizó un análisis de varianza paramétrico y no-paramétrico (Kruskall-Wallis), cuyo objetivo también fue el de verificar si existían diferencias significativas en los puntajes asignados por los jueces. Tanto el test paramétrico (valor- $p>0.05$ ) como el no-paramétrico (valor- $p>0,05$ ) arrojaron como resultado que no existen diferencias significativas entre ellos, con lo cual se verifica la validez del instrumento, toda vez que la variabilidad entre jueces es despreciable. 


\section{Resultados}

En el Test de Conciencia Metapragmática (CMP), el análisis se basó en un indicador denominado Nivel de Respuestas Metapragmáticas, el cual se obtiene dividiendo el número de respuestas metapragmáticas por el total de respuestas obtenidas, expresado en términos de porcentajes en una escala de $0 \%$ a 100\%. De esta manera, cada uno de los 82 participantes respondió 29 ítems; así, el 100\% de respuestas obtenidas correspondió a 2.578. De estas, el 27\%, es decir, 696 respuestas, fueron metapragmáticas y el 73\%, es decir, 1.882 fueron epipragmáticas.

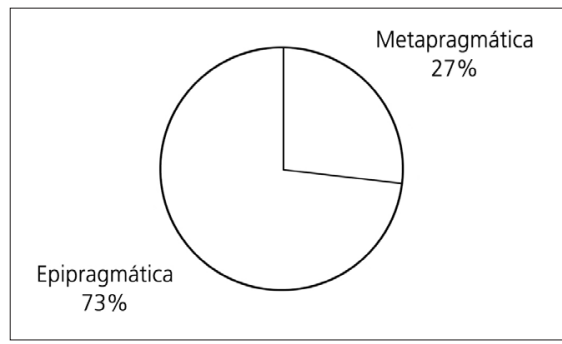

Gráfico 1. Porcentaje de respuestas obtenidas en la aplicación del Test de Conciencia Metapragmática.

Luego, se procedió a obtener una síntesis de los puntajes totales obtenidos en la CMP, en la cual se utilizó el Promedio y la Desviación Estándar, una como medida de tendencia central y la otra de Dispersión, respectivamente.

Con respecto al puntaje medio obtenido en la CMP, los niños tienen una mayor dificultad en las preguntas de tipo Referente Ambiguo, seguido por las Instrucciones Ambiguas, para finalizar con las de menor dificultad, dadas por las preguntas de tipo Diálogo Observado, como se aprecia en el Gráfico 2: 


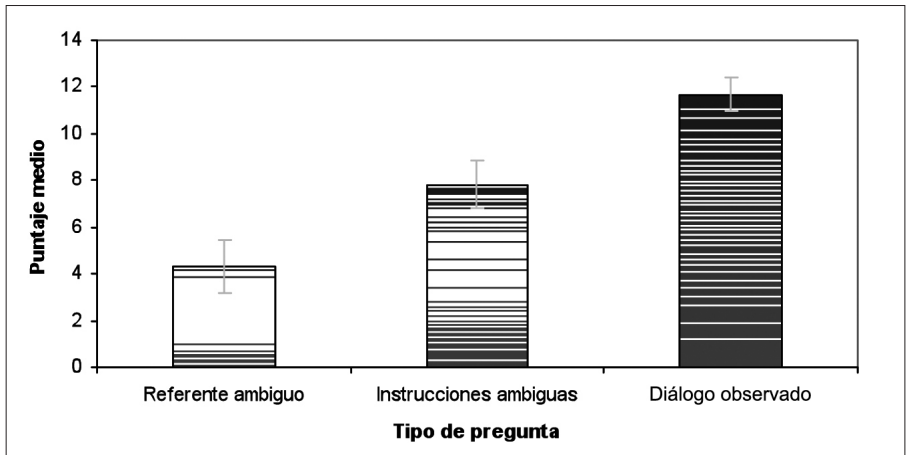

Gráfico 2. Puntajes promedio por tipo de pregunta, con sus intervalos de confianza del $95 \%$ de la Prueba Conciencia Metapragmática.

Entre los múltiples resultados que se obtuvieron a partir de la evaluación de la composición escrita para lo cual se utilizó la EHF, se pueden mencionar los siguientes: la respuesta más frecuente fue la Insuficiente, a la cual se le asignaba el puntaje 2; no se encontraron composiciones que merecieran los puntajes 5 ó 6, es decir, composiciones que fueran Idóneas o Excelentes. Por otro lado, se observó la ausencia de lenguaje figurativo, como ironías, metáforas o hipérboles; estas últimas en muy escaso número y, por tanto, no significativas. Se encontró, además, que las secuencias temporales de la narración eran poco claras y el conector temporal mayormente usado fue 'entonces' con una ausencia casi total de recursos hipotácticos y paratácticos.

En general, no se encontró el género descriptivo inserto en las narraciones como parte integral de ellas, ya que los participantes sólo se limitan a nombrar los personajes y los lugares donde alguna posible acción narrativa podría haber transcurrido. Las siguientes composiciones ilustran lo anterior (se ha conservado la redacción del original):

\section{Mifamilia}

Habia una vez una familia que vivia en pueblo chico y la Jabiera tenia dos Grandes Amigas, y se llamaba Maria José y la Barbara.

y las niñas nos iba a buscar para ir a jugar a la plaza con el 
Braulio y el Wilzon y ibamos a jugar a la pelota y los niños nos ganaron y después fuimos a tomar te a la casa de la Barbara.

y contamos penaduras y chistes y la Barbara conto penaduras de la llorona, el Braulio de el chuquicamata, la Maria José de la mano negra y yo de una calabasa.

y tambien contamos chiste y la Barabara se conto uno bueno de una niña que ba caminando porla calle, el Braulio no se quiso desir un chiste y todos les dijimos fome. (Puntaje 1)

\section{Una gran caja de sueños}

En un lugar muy lejano vivian un hombre llamado Alex que era muy millonario que tenia una caja pero no la podia abrir el busco una llave que tenia un corazon y al fin encontro la llave estaba en la caja fuerte de la casa corrio hasia la caja de sueños, la pudo abrir y de la caja salio una vos diciendo pide tu sueño y to are rrealidad. el hombre dijo mi sueño es que todos los niños pobres tengan casa y la vos dijo tu sueño se ara realidad y todos los niños pobres fueron a casa de Alex a agradeserle por pedir ese sueño y vivieron felises por ciempre. (Puntaje 3)

Los participantes, por lo demás, no recurrieron a la revisión de sus composiciones como parte integral del proceso de producir por escrito, como se pudo observar en una completa ausencia de borrones o del uso de la goma de borrar o de correctores líquidos.

Algunos de los temas fueron originales, pero otros se basaron en los que se incluyeron en las instrucciones para llevar a cabo la tarea de escritura o en las imágenes mencionadas en el apartado anterior. Los temas más recurrentes fueron la amistad, el amor, la ciencia ficción, el horror, los programas de televisión y los animales. Este último obtuvo la mayor frecuencia absoluta. El $96 \%$ de las composiciones se iniciaba con un título y el $85 \%$ de ellas comenzaba con "Había una vez..." Por último, la lectura de muchas de las composiciones se dificultó con los múltiples errores en ortografía y puntuación.

En otro orden de cosas, se observó en las composiciones un alto sentido del bien y del mal, es decir, los participantes dejan en claro quiénes son los héroes o heroínas y quiénes son los villanos, como también el gran papel que juega la oralidad como factor perturbador en la 
producción de los textos; en otras palabras, los participantes escriben como hablan. En cuanto a diferencias de género, las niñas presentan una calificación significativamente mejor que los niños, con un puntaje promedio de 2,2 para las primeras y de 1,7 para los segundos; solo los varones (en el 100\%) añaden una cuota de violencia a sus composiciones. A continuación, dos ejemplos del resultado inmediatamente anterior (se ha conservado la redacción del original):

(Sin título)

Habia una vez unos estraterrestres que bajaron al planeta Tierra y raptaron al presidente, Lo llevaron al planeta Marte donde estaba su rey él le díjo al presidente voi a conquistar su planeta Tierra y nadien me lo inpidira, bajaron otra vez, los policias les estaban disparando a la nave de los estraterrestres, ellos sacaron su pistola rayo laser, les es disparando a los policias, mataron a los policias y pucieron a los umanos como esclabos. (Puntaje 3)

(Sin título)

Habia una vez un carateca que tenia un hermano futbolista y Juan se enfrento al carateca y el carateca le volo la camara de fotos, un día cuando el juan se puso en carate los dos se enfrentaron y pelearon los dos caratecas Juan se enojo y le pego una patada y el otro carateca se enfuresio y le pego un combo en la estomago y una patada en la pierna, lo voto y le pego en el piso, cuando llego el futbolista el carateca Iuan le pego al futbolista y el otro carateca el hermano del futbolista lo defendio y le pego al carateca Juan una patada en toda la cara y e[ Juan se enojo y le trato de pegar pero lo voto al suelo y le piso la pierna y Juan se paro del piso y le quebro el Goku y el otro carateca le quebro la pierna de pies derechos. (Puntaje 1)

La prueba formal (ANOVA) permite verificar que esta diferencia es estadísticamente significativa (valor-p<0.01). 


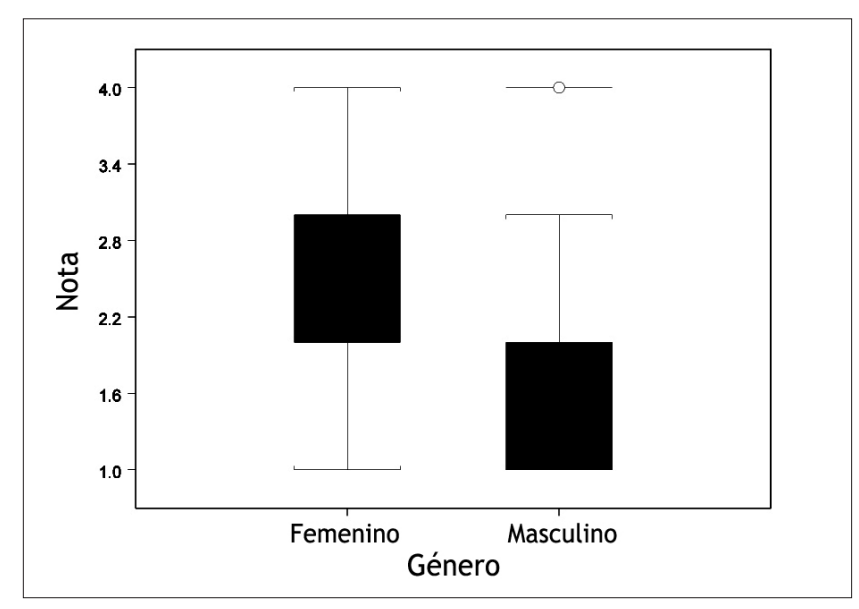

Gráfico 3. Gráfica de Cajón con bigotes para el puntaje medio, según género.

Para cada nivel de Desempeño en Composición de la prueba Producción Escrita, se obtuvo la proporción estimada de respuestas Metapragmática. Dado que en la prueba CMP, las respuestas factibles son Metapragmática o Epipragmática (1 ó 0), se utilizó un estimador de máxima verosimilitud para una variable aleatoria de tipo binomial, es decir, se estimó la proporción estimada de respuestas Metapragmática, expresión dada por:

$$
\hat{p}=\frac{\sum_{i}^{m} \sum_{j}^{n} x_{i j}}{n m},
$$

donde $\hat{p}$ corresponde a la proporción estimada de respuestas Metapragmática en cada clasificación de respuestas de la prueba PE; $x$ toma el valor 1 si la respuesta es Metapragmática y 0 si es Epipragmática; $n$ es el número de preguntas; $i$ indexa a los niños $(1, \ldots, m) ; j$ indexa a las preguntas $(1, \ldots n)$. Esta estimación se realizó para el total de la prueba y por subtest, de forma tal que el valor de $n$ en la expresión anterior, varía en función de esto. Además se expresa en porcentaje, es decir, en la medida en que es cercano a 100\%, el indicador refleja un mayor porcentaje de respuestas metapragmáticas con respecto al total de respuestas obtenidas.

Como se puede apreciar en la Tabla 1, los resultados obtenidos al analizar en forma conjunta ambas pruebas, muestran que a mejor desempeño en composición, aumentó el porcentaje promedio de respuestas metapragmáticas en los alumnos. En otras palabras, mientras más res- 
puestas conscientes se daban a los ítems de la prueba CMP, los participantes se manifestaban como mejores escritores.

Tabla 1. Porcentaje respuestas metapragmáticas y por nivel de desempeño.

\begin{tabular}{|c|c|}
\hline & \\
\hline Insatisfactoria & $25 \%$ \\
\hline Insuficiente & $24 \%$ \\
\hline Desequilibrada & $28 \%$ \\
\hline Suficiente & $31 \%$ \\
\hline
\end{tabular}

Cabe señalar que la relación proporcional 'a mejor escritura, más conciencia metapragmática' no se detectó por igual en todos los tipos de ejercicios que componían el instrumento para medir la comprensión oral de los niños (Gráfico 4). 


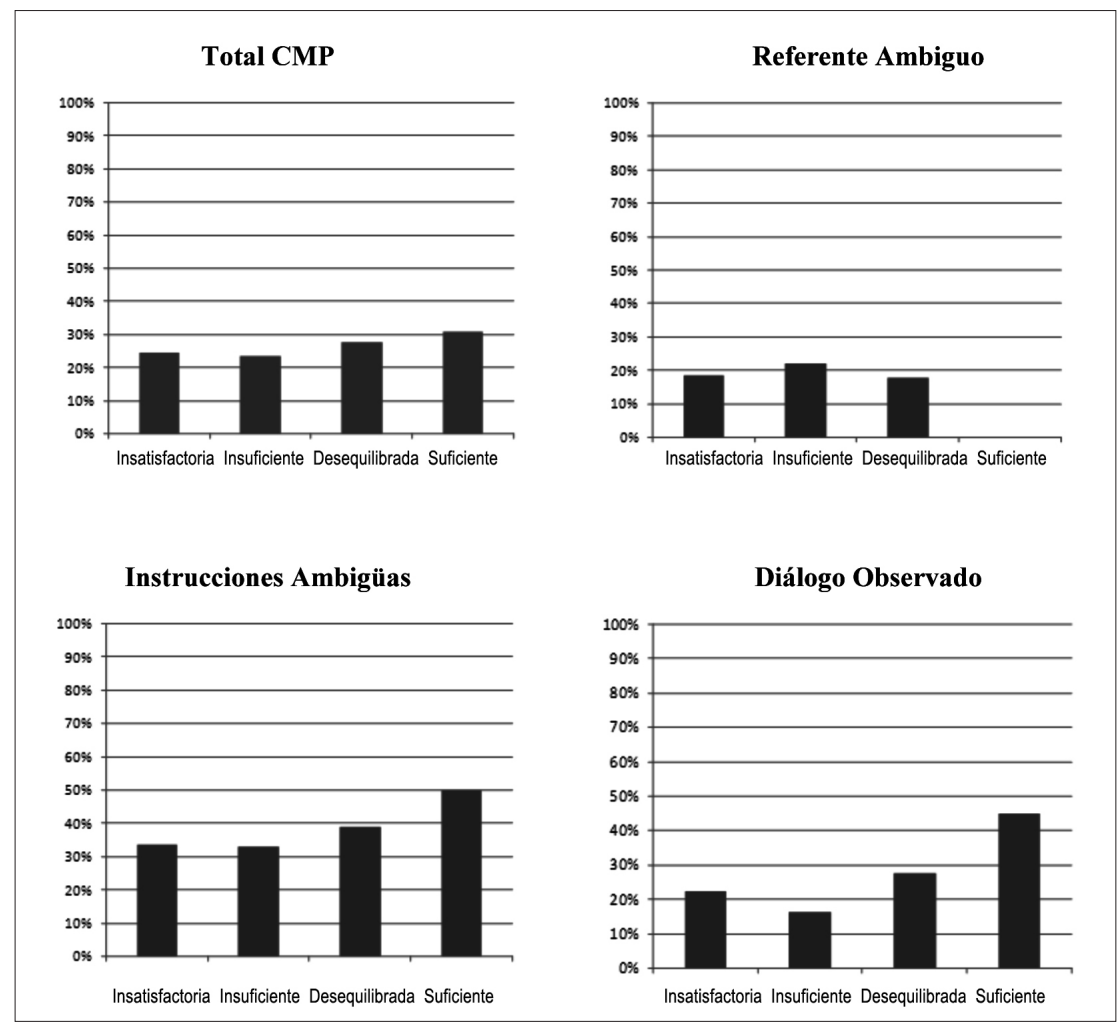

Gráfico 4. Porcentaje respuestas metapragmáticas por nivel de desempeño en composición escrita.

\section{CONCLUSIONES}

Este estudio intentó relacionar la conciencia metapragmática con la producción de discurso escrito en niños de ocho a ocho años once meses. Los instrumentos utilizados, los resultados obtenidos con su aplicación y el análisis correspondiente de aquellos permiten concluir que esta relación es directamente proporcional, es decir, a un mejor desempeño en escritura, mayor porcentaje de respuestas metapragmáticas.

Además, el análisis de los resultado permite aventurar que la conciencia metapragmática no 
ocurre en forma sistemática en todas las situaciones comunicativas, sino que depende de la manera en que se relaciona el contexto con el lenguaje utilizado. Asimismo, la relación proporcional 'a mejor escritura mayor conciencia metapragmática' no se detectó por igual en todos los tipos de ejercicios que componían el CMP.

Por otro lado, el ejercicio de la Prueba CMP más dificultoso para los niños fue el Referente Ambiguo, puesto que exige un manejo más acabado de los deícticos y no pareciera relacionarse con la habilidad para componer por escrito. En cambio, tanto los ejercicios de Diálogo Observado como los de Instrucciones Ambiguas resultaron más fáciles y se correlacionaron más estrechamente con la calidad de la producción escrita.

Finalmente, al menos tres son las proyecciones que pueden derivarse de la presente investigación. En primer lugar, un estudio que indague los aspectos de la composición escrita que se desarrollan en forma ontogenética para poder observar la posible influencia de los niveles de escolaridad en esta habilidad. En segundo lugar, un estudio que observe la relación entre conciencia metapragmática y producción escrita en niños mayores que los que participaron en esta investigación, es decir, adolescentes y adultos, con el fin de analizar cómo evoluciona dicha relación. Por último, explorar la posibilidad de incluir aspectos de la conciencia metapragmática en la instrucción de la producción escrita, ofreciendo de esta manera nuevas alternativas a la metodología que se implementa en las aulas de educación formal.

\section{REFERENCIAS BIBLIOGRÁFICAS}

Arnáiz, P., Castejón, J. L., Ruiz, M. S. \& Guirao, J. M. (2002). Desarrollo de un programa de habilidades fonológicas y su implicación en el acceso inicial a la lecto-escritura en alumnos de segundo ciclo de educación infantil. Educación, Desarrollo y Diversidad, 1, 29-51.

Benítez, R. \& Velásquez, M. (2000). Un análisis microestructural de la producción escrita de alumnos de $6^{\circ}$ y $8^{\circ}$ año de educación general básica. Lenguas Modernas, 26-27, 95-117.

Bialystok, E. (1992). Attentional control in children's metalinguistic performance and measures of field independence. Developmental Psychology, 4, 654-664.

Bitzer, L. (1966). The rhetorical situation, Philosophy and Rhetoric, 1, 1-14.

Brinton, A. (1981). Situation in the theory of rhetoric. Philosophy and Rhetoric, 14, 234-248.

Chaffee, J., McMahon, C. \& Stout, B. (2002). Critical thinking, thoughtful writing: A rhetoric with readings. Boston: Houghton Mifflin Company.

Chaney, C. (1994). Language development metalinguistic awareness and emergent literacy skills of 3-year-old children in relation to social class. Applied Psycholinguistics, 15, 371-394. 
Crespo, N. (2009). La medición de la conciencia metapragmática de los niños: Resolviendo la ambigüedad de la comprensión oral. RLA, 47(2), (en prensa).

Culioli, A. (1990). Pour une linguistique de l'enonciation. Opérations et représentations. Paris: OPHRYS.

Ede, L. \& Lunsford, A. (1984). Audience addressed/audience invoked: The role of audience in composition theory and pedagogy. College Composition and Communication, 35, 155171.

Flavell, J. H. (1985) Cognitive development. Englewood Cliffs, N.J.: Prentice Hall.

Flórez-Romero, R., Torrado-Pacheco, M. C. \& Magnolia-Mesa, C. (2006). Emergencia de las capacidades metalingüísticas. Revista Latinoamericana de Psicología, 3, 457-475.

Flower, L. \& Hayes, J. (1981). A cognitive process theory of writing. College Composition and Communication, 32, 365-387.

Gombert, J. (1992). Metalinguistic development. Chicago: University of Chicago Press.

Halliday, M. A. K. (1975). Learning how to mean: Explorations in the development of language. London: Edward Arnold (Publisher).

Hyland, K. (2007). Genre and second language writing. Ann Arbor, MI: The University of Michigan Press.

Jakobson, R. (1963). Essais de linguistique générale. Paris: Minuit.

Karmiloff- Smith, A. (1994). Más allá de la modularidad. Madrid: Alianza.

Levy, Y. (1999). Early metalinguistic competence: Speech monitoring and repair behavior. Developmental Psychology, 3, 822-834.

Mateos, M. (2001). Metacognición y educación. Buenos Aires: Aique.

McKee, H. \& Porter, J. (2008). The ethics of digital writing research: A rhetorical approach. CCC, 59, 711-749.

Peronard, M., Crespo, N., \& Velásquez, M. (2000). La evaluación del conocimiento metacomprensivo de la lectura en alumnos de Educación Básica. Revista Signos, 33(47), 131-145.

Piaget, J. (1987). Introducción a la epistemología genética. Paidós: Buenos Aires.

Porter, J. (1992). Audience and rhetoric. Englewood Cliffs, NJ: Prentice.

Puyuelo, M. \& Rondal, J. (2003). Manual del desarrollo y alteraciones del lenguaje: Aspectos evolutivos y patologías en el niño y el adulto. España: Masson.

R Development Core Team (2006). $R$ : A language and environment for statistical computing. $R$ Foundation for Statistical Computing, Vienna, Austria. ISBN 3-900051-07-0 [en línea]. Disponible en: http://www.R-project.org. 
Sistema de Medición de Calidad de la Educación (SIMCE). (2007, 2008, 2009) [en línea]. Disponible en: http://www.simce.cl/

Van Kleeck, A. (1994). Emphasizing form and meaning separately in rereading and early reading instruction. Topics in Language Disorders, 16, 27-49.

Vatz, R. (1973). The myth of the rhetorical situation. Philosophy and Rhetoric, 6, 154-161.

Verschueren, J. (2002). Para entender la pragmática. Madrid: Gredos.

White, S. \& Venneman, A. (2000). NAEP scoring of fourth-grade narrative writing. Education Statistics Quarterly, 4, 1-7.

Williams, J. (1998). Preparing to teach writing. Mahwah, NJ: Erlbaum. 
Anexo 1: Ejemplo esquematizado del ítem Referente Ambiguo

Imagen 1:

VOZ EN OFF:

Elige el gato con collar. Si tienes alguna duda, pregúntale al conejito. O si no, marca tu respuesta
Imagen 2: CONEJITO PREGUNTA:

¿Me puedes explicar tu duda? (RESPUESTA ORAL CONSIGNADA POR EL

EVALUADOR)

Abre el libro de las resnuestas.

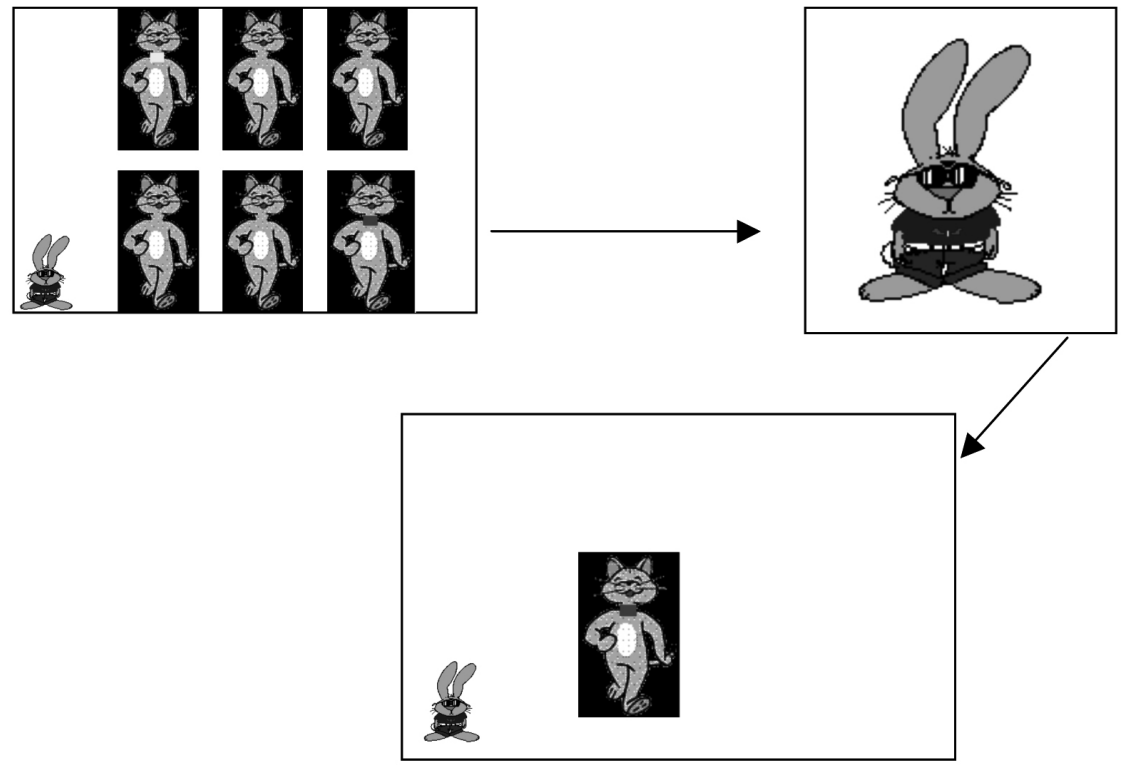

Imagen 3. CONEJITO DICE:

Está bien, hice trampa. Era el gato con collar rojo. 
Anexo 2: Ejemplo esquematizado del ítem Instrucciones Ambiguas

Imagen 1:

VOZ EN OFF:

Ahora descansemos. Juega conmigo a las cartas, debemos sacar una carta cada uno hasta que termine el mazo. La carta que tiene la flor señala el ganador. Gana el que tiene más cartas. ¿Entendiste? Entonces empecemos a jugar... ¿No entendiste? Entonces haz un clic aquí.
Imagen 2:

CONEJITO PREGUNTA:

¿Me puedes explicar tu duda? (RESPUESTA ORAL CONSIGNADA POR EL EVALUADOR)

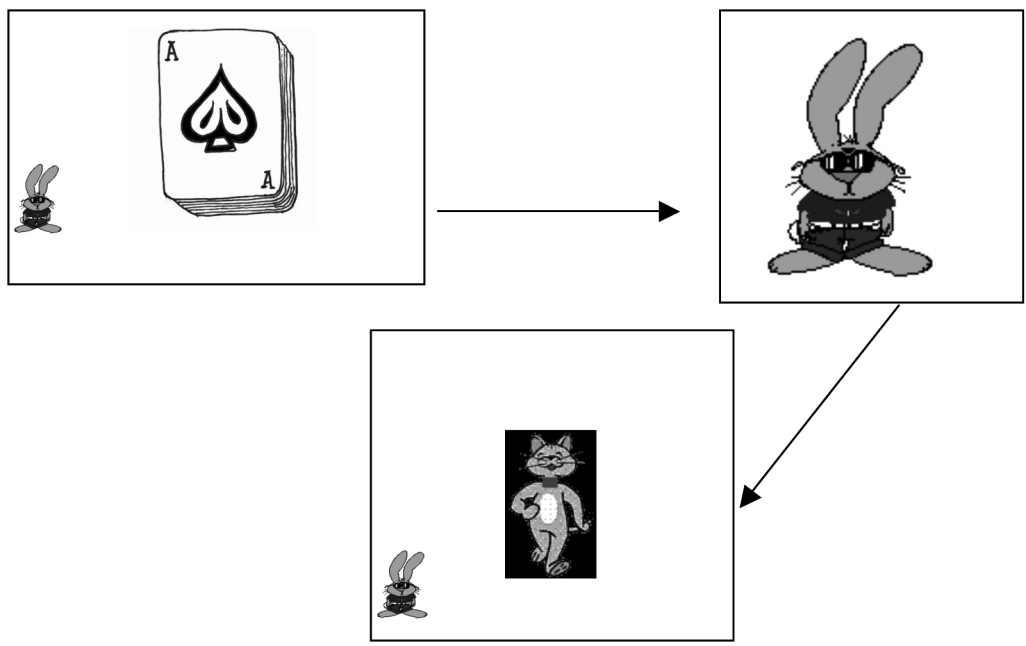

Imagen 3. CONEJITO DICE:

Está bien, no te expliqué bien. Cada uno saca una carta por vez y gana aquel que le toca la carta especial que es el As de picas. Ahora volvamos a jugar. Aprieta el botón 
Anexo 3: Ejemplo esquematizado del ítem Diálogo Observado

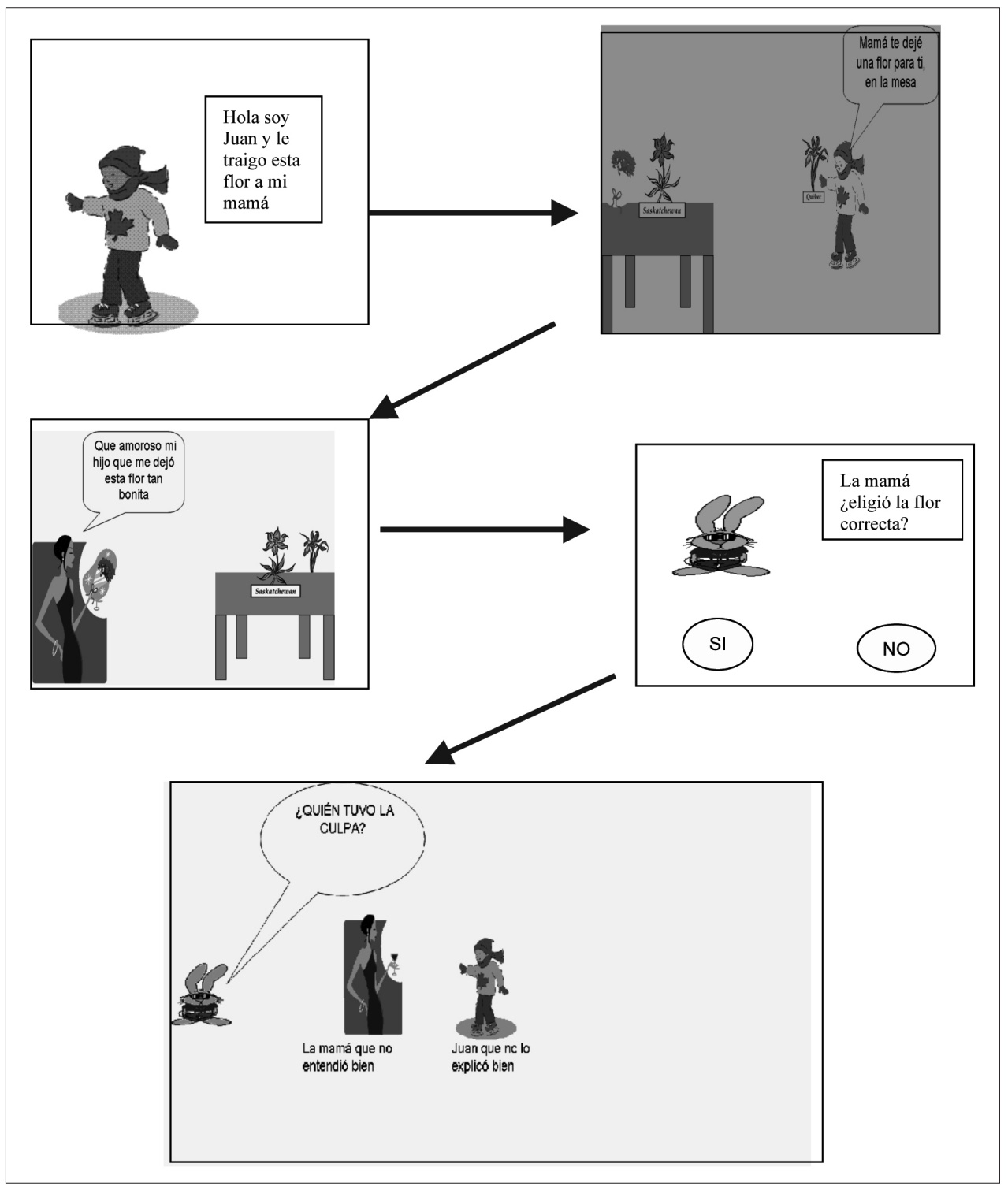




\section{Anexo 4: Tipos de Respuesta de la Escala Holística Focalizada}

\section{RESPUESTA INSATISFACTORIA}

\section{El texto:}

- no desarrolla una historia; si tiene una, es demasiado difícil de entender; sin apoyo; depende del dibujo.

- puede ser sólo un parafraseo de las instrucciones.

- muestra muy poca organización.

- no tiene ningún control sobre límites y estructuras oracionales.

- contiene oraciones cortas y simples en estructuras repetitivas.

- errores ortográficos y de puntuación que impiden severamente la comprensión.

- contiene elección léxica inexacta.

La acción:

- transcurre sin ningún escenario o contexto detallado, sin ninguna indicación de tiempo o lugar ("Había una niña. Le gustaban los dulces".)

- no se entiende qué eventos van primero o después de otros

- uno o dos eventos con muy poco o ningún conflicto (“Una vez había un gato. Al gato le gustaba la leche".)

Los personajes:

- el central no es una persona viva y real; sólo es un nombre en la página.

- uno o dos personajes planos y estáticos, con poca relación entre ellos.

\section{RESPUESTA INSUFICIENTE}

\section{El texto:}

- es desorganizado o poco centrado o claro; muy breve.

- tiene un control mínimo sobre límites y estructuras oracionales

- elección léxica a menudo inexacta

- errores gramaticales, ortográficos y de puntuación interfieren con la comprensión en la mayor parte del texto.

La acción:

- producción de sólo el comienzo del cuento o la historia.

\section{Los personajes:}

- introduce un personaje nuevo, pero no lo desarrolla más allá de ese punto.

- algo de pulimento en la descripción física.

- relación entre los personajes está dada por la acción. 


\section{RESPUESTA DESEQUILIBRADA}

El texto:

- puede faltar desarrollo en partes de la historia o ser repetitivo, o sólo es un comienzo bien escrito.

- organizado en partes; otras están desarticuladas y/o le faltan transiciones.

- control disparejo sobre límites y estructuras oracionales; algunas elecciones léxicas inexactas; expresiones trilladas y/o exageradas.

- errores gramaticales, ortográficos y puntuación interfieren a veces con comprensión.

La acción:

- es repetitiva; los eventos no están conectados para articular una historia coherente.

- el contexto pasa desapercibido para el lector

- a veces, no está claro qué evento sucedió primero.

- inicio de relación entre contexto y otros elementos narrativos (contexto futurístico para introducir alienígenas y nave espacial).

- episodio único y lineal con un claro comienzo, medio y fin, que contiene un problema, respuesta emocional, acción y resultado.

\section{Los personajes:}

- pulimento continuado de la descripción física, en particular características estereotípicas (verruga en la nariz).

\section{RESPUESTA SUFICIENTE}

\section{El texto:}

- organizado y claro, con cierto desarrollo.

- sin transiciones entre las partes.

- estructura oracional puede ser simple y poco variada.

- generalmente, elección léxica es apropiada (se ajusta a propósitos de la narrativa).

- errores gramaticales, ortográficos y puntuación no interfieren con la comprensión.

- contiene explicaciones para el lector

\section{La acción:}

- contexto se vuelve más esencial al desarrollo de la historia de modo explícito

- tiempo y lugar pueden ser esenciales a la trama.

- aumenta en complejidad con más de un episodio; cada uno de ellos con problema, respuesta emocional, acción y resultado.

- trama puede cambiar abruptamente.

\section{Los personajes:}

- motivaciones e intenciones que impulsan sus sentimientos y acciones a menudo a través de un punto de vista omnisciente limitado. 


\section{RESPUESTA IDÓNEA}

El texto:

- se apoya con razones pertinentes y/o ejemplos en su mayor parte.

- bien organizado, pero le faltan transiciones.

- uso de temas secundarios, a menudo vinculados con la trama mayor, pero a veces tangenciales.

- algo de experimentación con simplismo (en particular, lenguaje figurativo) que demuestra consideraciones al lector.

La acción:

- contexto puede servir más de una función y la relación entre funciones es más implícita y simbólica.

- relaciones más fuertes entre episodios, con resolución en uno de ellos que conduce al problema siguiente.

Los personajes:

- más pulimento en sentimientos y motivaciones

- aparecen características dinámicas entre ellos.

\section{RESPUESTA EXCELENTE}

\section{El texto:}

- se apoya en forma sistemática en razones y/o ejemplos bien elegidos

- puede que contenga estrategias persuasivas para transmitir argumentos

- es focalizado y organizado, con uso efecto de transiciones.

- variedad en la estructura oracional y precisión en elección léxica

- demuestra reflexión e imaginación, aunque en partes el lenguaje sea inapropiado.

- errores en gramática, ortografía y puntuación son pocos y no interfieren con la comprensión.

- cuidadosa elección de estructura narrativa.

La acción:

- transcurre en un lugar bien detallado.

- orden de eventos es siempre claro (en el pasado o en el futuro).

- trama principal múltiple y compleja; temas secundarios se relacionan de forma integral a los temas primarios.

\section{Los personajes:}

- la figura central se describe en detalle.

- pulidos y dinámicos a través de la descripción rica en afecto, intención y motivación. 


\section{Anexo 5: Instrucciones Tarea de Escritura}

\begin{tabular}{|c|c|}
\hline $\begin{array}{l}\text { Segu } \\
\text { quer } \\
\text { no ti } \\
\text { para } \\
\text { tu im }\end{array}$ & $\begin{array}{l}\text { ente, alguien alguna vez te ha contado un cuento o has leído alguno. En esta ocasión, } \\
\text { s que tú escribas tu propio cuento, el cual será llevado a padres y niños de otro país que } \\
\text { n la posibilidad de escuchar o de leer cuentos como tú. Te damos algunas sugerencias } \\
\text { inventes tu cuento. Si no te gustan estas sugerencias, puedes crear el tuyo propio con } \\
\text { nación: }\end{array}$ \\
\hline Suge & cias: \\
\hline 1. & un caballo salvaje \\
\hline 2. & niños que podían volar \\
\hline 3. & una caja de cuentos \\
\hline 4. & hormiguitas \\
\hline 5. & superhéroes \\
\hline 6. & un programa de TV \\
\hline 7. & una película \\
\hline 8. & las brujas y los magos \\
\hline 9. & los duendes \\
\hline 10. & las ciudades perdidas \\
\hline 11. & los payasos \\
\hline 12. & los extraterrestres \\
\hline 13. & lo que pasó en un paseo \\
\hline 14. & mis mascotas \\
\hline 15. & mis dibujos animados favoritos \\
\hline
\end{tabular}


Anexo 6: Muestras de composiciones de algunos participantes. Los números en paréntesis corresponden al puntaje asignado por los jueces. Ninguna composición obtuvo puntaje 6 .

\section{Los supererues de la Serena (1)}

Habia una ves en Serena rovaban y no eccistia nadie que podia salvarlos.

Undia llego mas gente era una familia de 6 personas una la mamá se llamaba Lorena El papá Carlos La hermana Marjo Tamara La ultima de las mujeres Rocio y los gemelos Matias y Esteban en Gilla les desian "La Superfamilia".

A la Mamá le decian la mujer eleastica al papa le decian el fortachon a la hermana mañor le dician la imbicible y a los gemelos los fugas llegara trabajar y aestudiar en el insuco ya trabajar en la elegante.

Los Cuatro hermanos se portaron muy bien y salvaron toro y unca más robaron en Serena ni en Coquimbo.

\section{Los amigos de los animales (2)}

Un dia los amigos se fueron de paseo al bosque no sabian a donde estaban sus familias no los encontraron pero encontraron un refugio grande era una selva después mientras dormian unos animales las molestaron las niñas gritaron de susto pero les gusto la selva se quedaron a vivir comian cosas de la selva que les daba su padre el mono y su madre mona que las adopto en la selva pasaron los años las amigas crecieron mucho nunca dejaron de divertirce asta que el leon llego furioso queria que se fueran todos de la selva todos le tenian miedo al leon feroz todos no tenian casas donde refugiarce pero las amigas se les ocurrio hacer casa para los animales.

\section{La familia en navidad (3)}

Abia una vez una familia muy feliz y abia un hombre que se encontro con una mujer en el mol y después se pusieron a comersar y se conocieron y despues se enamoraron y despuez se casaron y tuvieron hijos. tuvieron un hijo y una hija y despues los ijos cresian y cresian hasta que fueron al colegio y después pasaron todos los meces y pasaron hasto la navidad y llego la navidad y después los niños isieron unas carta del viejo pascuero en el colegio y después el niño chiquitito se puso a llorar por que no encontro lo carta del viejo por que lo ivan a yevar al mol para el viejo pascuero y despuez la hermana la llevo no mas y después iso otro y se le volvio a perder y al final yego navidad y el viejo pascuero igual le dejo un regalo y se puso 
muy contento por que hera un hauto control remoto y le encanto su regalo de navidad y el no creia en el viejo pascuero y después viajo al polo norte y lo vio y después siempre creyo en el y haora le encanto la navidad.

\section{El caballo, el dueño y un cazador (4)}

Habia una vez un caballo muy tierno, abiloso, respetuoso. Un dia vio a un hombre que no tenia familia el estaba muy solo. Pero el caballo fue donde el acompañarlo le dijo - hola ¿como te llamas ven a jugar conmigo- le dijo el caballo - bueno yo me llamo fernando. De pronto escucharon ruido -dijo el hombre- es un cazador!!! aranquemos!!! Si dijo el caballo y el cazador enpezo a disparar pero no lastimo a nadie el hombre se subio al caballo y escaparon después el cazador-dijo-finalmente los encontre pero el hombre salto del caballo y se escondio en unas ramas después el cazador iba a matar al caballo pero no pudo porque el hombre le disparo justo en el corazon y se murio después fueron a jugar con la naturaleza jugaron todo el dia y se hicieron muy amigos. El caballo y el hombre se hicieron una casa para vivir en paz de los enemigo y el hombre se hizo dueño del caballo.

\section{José y el bosque mágico (5)}

José era un niño de ciudad muy bueno de 7 años y le encantaba la naturaleza. Un día de Primavera con toda su familia fue de paseo a el campo; fue a jugar con sus hermanos a la escondida y corrió hasta que se perdió entre los árboles del bosque, solo sin ninguna pista de vida.

-Cabum!- Derrepente apareció un duende verde muy pequeño solo media $60 \mathrm{~cm}$., luego el duende se empezó a mover al ritmo de una música de carnaval y aparecieron más, y más, y muchos más seres mágicos que bailaban y se dió cuenta que era un bosque mágico. Mientras su familia lo vuscaban y lo buscaban hasta que apareció la noche y José seguía en el bosque mágico con todos esos seres extraños.

Paso el tiempo y lo seguían buscando y José cada vez más amigo se hacía de esos seres; hasta que un día la familia se adentró en los matorrales y encontraron el bosque mágico extrañados de dots esos seres y se adentraron más y más alla hasta que encontraron a José le ablaron y se fueron a la casa fuera de ese bosque y cuando llegaron José contó todo lo que le había pasado $y$ felices por siempre. 